\title{
0 enquadramento do aborto na mídia impressa brasileira nas el eições 2010: a exclusão da saúde pública do debate
}

\author{
The stance of abortion in the Brazilian printed media \\ ahead of the 2010 presidential elections: \\ the exclusion of public health from the debate
}

${ }^{1}$ Instituto deBioética, Direitos Humanose Gênero, Universidade Federal da Bahia. Rua Barão deGeremoabo $s / n$, Campus Universitário de Ondina, Ondina. 40170-115 Salvador BA. maluzes@gmail.com
Abstract Objectives: this article presents the results of research to monitor theBrazilian printed media in order to identify the stance of the abortion issue during the period from July 6 to 0 ctober 29, 2010, which was the period of the official presidential campaign in Brazil. Methodology: based on the monitoring of 28 printed media ve hicles (newspapers and magazines) with nationwide circulation, the research selected 464 texts, of which 434 were considered valid for the study. Themedia studied included stories, reports, notes, opinion columns, interviewsand lettersfrom readers. Results. although abortion was widely mentioned in Brazilian news coverage of the presidential campaign in 2010, with an average of four texts published per day, the stanceadopted for the issuewas not from thestandpoint of public health. Among the 434 texts analyzed, only one report explicitly addressed epidemiological data linking abortion to women's health. In the other texts, the positioning of abortion was guided by the electoral stance that associated it with the disputefor the votes of the religious communities and conservative voters.

Key words Abortion, Positioning, Stance, Reproductive health, Public health, Election campaign
Resumo Objetivos. 0 artigo apresenta os resultados de uma pesquisa de monitoramento da mídia impressa brasileira para identificar as formas de enquadramento do tema do aborto durante 0 período de 6 de julho a 29 de outubro de 2010, período oficial da campanha eleitoral para a Presidência da República. M etodologia: a partir do monitoramento de 28 veículos impressos de circulação nacional (jornais e revistas), a pesquisa recuperou 464 textos, dos quais 434 foram considerados válidos para o estudo, entre matérias, re portagens, notas, colunas de opinião, entrevistas e cartas de leitores. Resultados. embora o aborto tenha sido amplamente citado na cobertura jornalística da mídia impressa brasileira durante a campanha eleitoral para a Presidência da República em 2010, em uma média de 4 textos publicados por dia, 0 enquadramento adotado para 0 tema não foi o da perspectiva da saúde pública. Dos 434 textos analisados, apenas 1 reportagem abordou explicitamente dados epidemiológicos relacionando 0 aborto à saúde da mulher. Nos demais textos, 0 agendamento do tema foi pautado mediante enquadramentos eleitorais associando-o à disputa dos candidatos pel os votos das comunidades religiosas e do eleitorado conservador. Palavras-chave Aborto, Agendamento, Enquadramento, Saúde Reprodutiva, Saúde Pública, Campanha eleitoral 


\section{Introdução}

A imprensa, em um país democrático e laico, é um dos principais agentes formuladores do elenco de temas que compõem o repertório da opinião pública. Seu papel como ator social para o agendamento das questões que vão nortear o debate na esfera pública é fundamental ${ }^{1-3}$. A partir das formas sob as quais a imprensa aborda um tema, pode haver diferentes repercussões na agenda pública nacional e, consequentemente, na proposição ena formulação de políticas públicas que promovam mudanças de cenário. 0 aborto inseguro é um dos temas na agenda de saúde pública no Brasil com grandes impactos sobre a saúde das mulheres no país $s^{4-7}$.

$\mathrm{Na}$ imprensa nacional, $\mathrm{o}$ aborto é pautado majoritariamente pela via do discurso moral, religioso, policial e jurídico8-10. Nas notícias sobre aborto, as vozes religiosas são as mais legitimadas, sejam elas da I greja Católica ou de lideranças das igrejas evangélicas, sobretudo dasigrejas neopentecostais. Além dessas, são ouvidas fontes policiais ou jurídicas, nos casos do noticiamento de clínicas clandestinas denunciadas por realizar aborto, prisão de profissionais de saúde acusados da prática e indiciamento de mulheres que recorreram à prática ilegal9,10. Na pauta cotidiana da imprensa brasileira, há poucas exceções ao viés narrativo das circunstâncias penais e criminais envolvendo mulheres que se submetem a abortos inseguros em clínicas clandestinas.

Uma dessas exceções foi o agendamento do aborto ocorrido nos meios de comunicação quando do debate travado no Supremo Tribunal Federal (STF) em torno da A ção da Anencefalia, apresentada em 2004. ${ }^{\circ}$. A ação propunha 0 direito das mulheres à antecipação terapêutica do parto nos casos degravidez defetos com anencefalia, anomalia incompatível com a vida extrauterina, o que, em 2005, levou o STF a realizar as primeiras audiências públicas de sua história, com ampla cobertura da imprensa. 0 agendamento feito pelos meios de comunicação estendia o debate sobre o direito legal ao aborto em casos de anencefalia a polêmicas travadas entre autoridades do campo da saúde e da religião em relação ao aborto em geral.

Ao fazer com que determinado assunto seja incluído na pauta jornalística, diz-sequeos veículos de imprensa agendam um tema, configurando 0 processo chamado de agenda-setting ${ }^{1,2}$. A forma como esse tema é abordado e apresentado à opinião pública, ou seja, a partir da escolha de quais enfoques ou de quais vozes os veículos de imprensa recorrem para ouvir, entrevistar e, com isso, autorizá-las e legitimá-las diante de uma questão, é o que se chama de enquadramento. 0 termo, utilizado para designar o modo como os meios de comunicação constroem suas narrativas e defendem teses sobre o que noticiam, foi metaforizado para o campo da produção e publicação de informações jornalísticas a partir do conceito de framing, de Irving Goffman. 0 conceito define as molduras e os comportamentos dos atores sociais no contexto público a fim de estabelecer de que modo desejam ser avaliados por seus interlocutores ${ }^{11-15}$. Simplificadamente, pode-se dizer que a "agenda" dos veículos de imprensa pode ser traduzida como "o que" estes abordam, enquanto que 0 "enquadramento" diz respeito à forma "como" se dão determinadas abordagens. Nesse processo, tanto as notícias publicadas como os modos como os fatos são narrados não podem ser considerados neutros quanto a seus efeitos sobre a opinião pública.

Esses dois dispositivos - os temas narrados pela imprensa e os modos como ela os narra - e o seu poder de agendar os temas e de produzir reflexos na sociedade a partir dos enquadramentos são estrategicamente planejados pelos meios de comunicação visando dar ao público uma percepção de que o campo jornalístico se pauta em critérios de objetividade. No entanto, os estudos de enquadramento revelam como a escoIha do viés de abordagem e a seleção das fontes contribuem para que determinadas teses seaproximem ou sedistanciem dosinteresses políticose ideológicos do poder hegemônico ${ }^{16-18}$.

Pesquisas mais recentes sobre os efeitos do poder político do enquadramento adotado pelos grandes veículos de imprensa nos Estados Unidos sobre a opinião pública apontam para mudanças de comportamento, favorecendo a ampliação da compreensão de determinados temas, sobretudo aqueles relacionados aos impactos da tecnologia sobre a saúde ${ }^{13,17}$. A mudança de comportamento de leitores de grandes veículos de imprensa credita-se à diversificação de vozes ouvidas pela comunidade jornalística, o que amplia a diversidade e o viés contraditório de perspectivas ${ }^{13,15}$.

0 objetivo deste estudo é apontar, a partir do monitoramento de 28 veículos noticiosos impressos brasileiros, as formas de enquadramento do aborto predominantes durante o período oficial da campanha eleitoral para a Presidência da $\mathrm{Re}$ pública no Brasil ( 6 de julho a 29 de outubro de 2010). Partindo da recuperação de 464 textos, dos quais 434 foram analisados em profundidade, 
buscou-se identificar os principais dispositivos usados na cobertura do aborto na campanha eleitoral. A perspectiva da pesquisa foi observar em que medida a questão da saúde pública foi contemplada na cobertura dos veículos de comunicação sobre o aborto como tema amplamente agendado durante a campanha eleitoral de 2010.

\section{M etodologia}

A pesquisa empírica que subsidiou este artigo foi realizada em uma base de dados composta por 464 textos publicados em um universo de 28 ve ículos de imprensa brasileiros de circulação nacional (jornais e revistas). A pesquisa de recuperação dos textos, compreendendo matérias, reportagens, reportagen sespeciais, notas, colunas, artigos de opinião, entrevistas e cartas de leitores, abrangeu o período de 6 de julho de 2010 a 29 de outubro de 2010, período oficial da campanha eleitoral para a Presidência da República. A primeira data marca o dia seguinte à homologação das candidaturas no Tribunal Superior Eleitoral (TSE) e a segunda marca a véspera da realização do segundo turno das eleições, no dia 30 de outubro, disputado pelos candidatos José Serra (PSDB) e Dilma Rousseff (PT).

D os 464 textos, publicados em 13 veículos ( 9 jornais e 4 revistas), 434 foram considerados válidos. Quinze dos veículos impressos monitorados não veicularam textos sobre 0 assunto no período compreendido pela pesquisa e o descarte de 30 textos entre os recuperados deveu-se ao fato de referirem-se a outros países, sem vinculação com o contexto brasileiro pesquisado. A pesquisa empírica, que usou os termos "aborto" e "eleições" como palavras-chave de busca, foi realizada mediantea contratação deuma empresa especializada em clipagem de notícias. Os critérios considerados para definir a condição de veículo impresso de circulação nacional foram os adotados rotinei ramente pela empresa de clipagem, que leva em conta dispositivos próprios relacionados ao volume de circulação dos veículos no país e não apenas a relevância destes em determinada região.

A opção por monitorar veículos noticiosos exclusivamente impressos e de circulação nacional, descartando-se os veículos regionais ou de suporte on-line, visou evitar a duplicação ou até mesmo a repetição de textos. A dinâmica de publicação de notícias on-line e em veículos regionais adota a tendência editorial de adquirir informações produzidas pelas grandes agências de notícias, de propriedade dos veículos nacionais, inflacionando o universo de textos recuperados.

A análise aplicou aos textos publicados um conjunto de perguntas elaboradas com o propósito de mapear a natureza da pauta e delinear 0 agendamento e enquadramento do aborto: se como questão primária ou secundária. Buscouse também traçar um mapa das fontes e autoridades ouvidas e/ou citadas pelos jornalistas nos textos analisados, identificando-as quanto ao sexo e aos papéis profissionais exercidos.

Considerou-seo aborto como objeto de abordagem na condição de questão primária nos casosem quenão apenaso tema era citado explicitamente e com destaque, mas também em que a pauta e a matéria eram diretamente sobre a pre sença do aborto nas eleições. Isso sedeu, por exemplo, nas matérias que discutiam o fato de a posição de um candidato sobre o aborto ser considerada ambígua por uma determinada comunidadereligiosa ao ponto deesta conclamar seusfiéisa rejeitar tal candidatura. Já no enquadramento do aborto como questão secundária, inscreveram-se os textos nos quais, embora se mencionasse 0 aborto, a pauta e 0 assunto principal da matéria eram outros. Exemplos de enquadramento do aborto como questão secundária são matérias em que o programa de governo de um dos candidatos era questionado sobre as razões pelas quais o texto original apresentado inicialmentenaJustiça Eleitoral tinhasido reformulado, retirando-setre chos considerados polêmicos relacionados a direitos humanos, união civil entre pessoas do mesmo sexo e aborto, entre outros temas.

\section{Resultados}

Dos 28 veículos monitorados e considerados como de circulação nacional, somente 13 concentraram a publicação dos 434 textos considerados válidos para a pesquisa: 9 jornais e 4 revistas. A avaliação do tom editorial dos textos seguiu duas variáveis: o elemento informativo que norteou a elaboração da pauta e a natureza da informação publicada sobre aborto no contexto da campanha. Dessa maneira, os textos foram classificados como tendo o aborto na agenda primária ou secundária para o enquadramento. A Tabela 1 apresenta o mapa do agendamento/ enquadramento do aborto nos textos:

Entre os veículos de circulação nacional monitorados, o maior volume de textos publicados sobre 0 aborto no contexto da campanha concentrou-senosjornais O Estado deS. Paulo (123 
textos, 28,34\%), Folha de S. Paulo (101 textos, $23,27 \%$ ), O Globo ( 86 textos, 19,82\%), Correio Braziliense ( 51 textos, 11,75\%) eValor Econômico (34 textos, 7,83\%). Os resultados explicitados na Tabela 1 indicam o tipo de enquadramento do aborto: 251 textos (58\%) o enquadraram como questão secundária, e 183 textos (42\%), como questão primária.

A pesar da presença do aborto como tema ostensivo durantetoda a campanha el eitoral, com uma publicação média de 4 textos por dia na imprensa escrita, a maioria das abordagens 0 enquadrava como uma questão secundária, como tabu moral. As narrativas noticiosas publicadas apontavam para o cuidado, por parte dos candidatos, com a possibilidade de serem associa-

Tabela 1. Como o aborto é tratado nos textos analisados.

\begin{tabular}{lrrrr}
\hline \multicolumn{1}{c}{ Veículo } & \multicolumn{2}{c}{$\begin{array}{c}\text { Questão } \\
\text { primária }\end{array}$} & \multicolumn{2}{c}{$\begin{array}{c}\text { Questão } \\
\text { secundária }\end{array}$} \\
\hline Brasil Econômico & 3 & $38 \%$ & 5 & $63 \%$ \\
Correio Braziliense & 18 & $35 \%$ & 33 & $65 \%$ \\
Folha de S. Paulo & 45 & $45 \%$ & 56 & $55 \%$ \\
Jornal da Câmara & 3 & $100 \%$ & 0 & $0 \%$ \\
Jornal do Brasil & 0 & $0 \%$ & 2 & $100 \%$ \\
Jornal do Senado & 0 & $0 \%$ & 1 & $100 \%$ \\
O Estado de S. Paulo & 51 & $41 \%$ & 72 & $59 \%$ \\
O Globo & 44 & $51 \%$ & 42 & $49 \%$ \\
Carta Capital & 1 & $20 \%$ & 4 & $80 \%$ \\
Época & 2 & $29 \%$ & 5 & $71 \%$ \\
Istoé & 3 & $100 \%$ & 0 & $0 \%$ \\
Veja & 4 & $40 \%$ & 6 & $60 \%$ \\
Valor Econômico & 9 & $26 \%$ & 25 & $74 \%$ \\
Total & 183 & $42 \%$ & 251 & $58 \%$ \\
\hline
\end{tabular}

Fonte: Projeto Aborto em pauta - fissuras no enquadramento do aborto na imprensa brasileira. dos a uma postura favorável à ampliação da le gislação sobre o tema e a uma consequente perda de votos junto ao eleitorado conservador, contrário a essa perspectiva. Ou seja, embora se tenha tratado de um tema de ampla repercussão noticiosa durante as eleições presidenciais de 2010, a abordagem passou ao largo de informações amplas que descrevessem o assunto no contexto e no cenário de saúde pública no Brasil. 0 tema era objeto de repercussão nacional na imprensa, mas, ao mesmo tempo, era enquadrado majoritariamente como questão secundária nas pautas e nos textos publicados.

Há ainda um segundo descompasso: mesmo com $42 \%$ dos textos publicados tendo adotado uma perspectiva do aborto como questão primária, inexiste em quaisquer dessas narrativas informativas a história de mulheres que viveram a experiência do aborto. Uma única matéria, publicada pelo jornal 0 Globo, em 10 de outubro de 2010, noticia diretamente os índices de abortamento clandestino no Brasil. Intitulada "M ortes em Silêncio", a única reportagem do universo de textos analisados tem como destaque principal a magnitude de mulheres que morrem anualmente no país em consequência das sequelas provocadas por aborto inseguro e malsucedido. Não há, no entanto, entrevista com nenhuma mulher quetenha tido essa vivência em seu contexto familiar ou social ou que tenha se submetido ao aborto e experimentado sequelas do procedimento. Esse silenciamento sobre as experiências das mulheres evidencia a exclusão da saúde pública no debate travado no cenário político ejornalístico durante o período das eleições.

Q uanto às fontes ouvidas ou citadas nos veículos monitorados (Tabela 2), nos 434 textos analisados, em 214 (42\%) deles elas são exclusi-

Tabela 2. Fontes ouvidas e/ou citadas nos textos

\begin{tabular}{lrrrrrrrr}
\hline Fontes ouvidas e/ou citadas & \multicolumn{2}{c}{ Homem } & \multicolumn{2}{c}{ M ulher } & \multicolumn{2}{c}{ Ambos } & \multicolumn{2}{c}{ Total } \\
\hline Religiosa católica & 61 & $100 \%$ & 0 & $0 \%$ & 0 & $0 \%$ & 61 & $100 \%$ \\
Religiosa evangélica & 23 & $96 \%$ & 1 & $4 \%$ & 0 & $0 \%$ & 24 & $100 \%$ \\
Feminista & 0 & $0 \%$ & 8 & $100 \%$ & 0 & $0 \%$ & 8 & $100 \%$ \\
Saúde & 4 & $57 \%$ & 2 & $29 \%$ & 1 & $14 \%$ & 7 & $100 \%$ \\
Jurista & 3 & $100 \%$ & 0 & $0 \%$ & 0 & $0 \%$ & 3 & $100 \%$ \\
Acadêmico & 21 & $57 \%$ & 13 & $35 \%$ & 3 & $8 \%$ & 37 & $100 \%$ \\
Cientista político & 10 & $83 \%$ & 2 & $17 \%$ & 0 & $0 \%$ & 12 & $100 \%$ \\
Político & 92 & $43 \%$ & 80 & $37 \%$ & 43 & $20 \%$ & 215 & $100 \%$ \\
Nenhuma & & & & & & & 145 & $100 \%$
\end{tabular}

Fonte: Projeto A borto em pauta - fissuras no enquadramento do aborto na imprensa brasileira 
vamente masculinas, em 106 (21\%) textos, são femininas, e em apenas 47 ( $9 \%$ ) textos há fontes simultaneamentemasculinas efemininas. Quando combinadas à religião, entre as fontes citadas como pertencentes à religião católica, todos os 61 textos que os citam (100\%) dão voz a homens; entreos 24 textos que citam fontes no universo dos textos, $23(96 \%)$ citam homens e apenas um cita fontes femininas (4\%). D os 8 textos que citam feministas, todos ouvem mulheres (100\%); além disso, em 12 textos as vozes citadas são de cientistas políticos: 10 citam homens ( 83\%) e 2 citam mulheres (17\%). No universo das 215 textos cujas fontes são de autoridades políticopartidárias, 92 textos (43\%) citam homens e 80 (37\%) citam mulheres. Em 43 textos (20\%), homens e mulheres são citados. Dos 7 textos que citam autoridades do campo da saúde, 4 (57\%) citam homens, 2 (29\%) citam mulheres 1 cita homens emulheres. Em 145 (33,41\%) dostextos analisados, nenhuma fonte é citada ou entrevistada. 0 maior universo de mulheres citadas ou ouvidas concentra-se nos textos em que as fontes são autoridades políticas: em $80(18,43 \%)$ textos, exclusivamente mulheres são citadas. Em 43 $(9,9 \%)$ outros textos em que as fontes citadas são autoridades políticas, estas são pessoas de ambos os sexos.

0 agendamento se deu sob o enquadramento em que predominavam os valores religiosos e não como tema de política de saúde. A perspectiva moral vinculada a princípios religiosos foi utilizada durante toda a campanha eleitoral como mecanismo para angariar votos. M esmo com o aborto clandestino sendo uma das principais causas demorte demulheres e gerador deíndices epidemiológicos com ampla repercussão na saúde de mulheres em idade reprodutiva, somente uma reportagem ("M ortes em Silêncio"), publicada no jornal $\mathrm{O}$ Globo, enfrentou diretamente esse cenário.

Entreos $18(4,1 \%)$ textoscujo enquadramento extrapolava o tom majoritariamente pautado pelas candidaturas, estendendo a abordagem para além do tabu, da moralidade e do embate religioso, apenas a reportagem de 0 Globo enquadrou o tema sob a perspectiva da magnitude da mortalidade de mulheres por aborto no Brasil. N os demais prevalecem abordagens vinculadas ao aborto como tema geral, a pesquisas de opinião sobre como a sociedade brasileira avalia a legislação vigente sobre o tema, e a como determinadas comunidades, como a de magistrados, avaliam 0 aborto no contexto de suas vidas pessoais. Há ainda a abordagem de articulistas, cujo tom predominante é o de crítica aos modos como 0 aborto misturou-se à religião no contexto eleitoral.

Nesse cenário, alguns dos títulos dos 18 textos classificados na pesquisa como narrativas cujo conteúdo situa o aborto como uma questão de saúde com repercussão social, ilustram o tom editorial dos mesmos: "O corpo como campo de batalha"; "O aborto além da vida"; "Os perigos da simplificação"; "O aborto da política pública"; "Pelo amor de Deus, não copiem os Estados Unidos"; "A questão do aborto, revisitada"; "Tributo à hipocrisia", entre outros. Identificou-se também o posicionamento de leitores através de cartas e o de jornalistas através de notas curtas publicadas em colunas da editoria de Política em veículos como Folha de S. Paulo, O Estado de S. Paulo e Correio Braziliense.

Como as fontes mais citadas nos textos são vozes de outros cenários que não aqueles que têm como ponto nuclear de argumentação dados relacionados às circunstâncias do aborto como uma questão de saúde eà punição policial ejurídica das mulheres, a discussão sobreaborto na imprensa no período se reduziu à polemização moral e ao contexto politico-partidário e religioso. A esfera da saúde pública não foi contemplada, eo principal indicativo dessa exclusão do debate aparece na concentração de fontes masculinas, em primeiro lugar, e em seguida político-partidárias e religiosas. Em 416 textos $(95,8 \%)$, a abordagem do tema não se pautou no marco aborto-saúde-sociedade, mas no enquadramento da campanha eleitoral em relação à disputa, segundo a ótica dos candidatos hegemônicos, dos votos das comunidades religiosas e do eleitorado conservador.

Se apenas $18(4,1 \%)$ dos 434 textos analisados contemplam aspectos do aborto relativos à saúdee às repercussões sociais do fenômeno, mais ilustrativo ainda do quanto o enquadramento dado pela imprensa e sua cobertura não deu ênfase a esse aspecto éo fato de que apenas 3 textos destes 18 serem reportagens produzidas por jornalistas dos veículos que as publicaram. I sso significa que, dos 18 textos que de algum modo cotejam a relação entreaborto esaúde pública, apenas foram construídos a partir de pautas geradas nas redações dos veículos de comunicação, ao invés de serem produto de reflexão de colunistas e especialistas externos. Três textos equivalem a apenas $0,7 \%$ do universo dos 434 textos publicados por esses veículos durante o período eleitoral sobreo assunto. Essas três matérias apresentam levantamento de dados numéricos, apu- 
ração de dados relacionados ao aborto a partir de entrevistas e contextualização com aspectos relacionados a dados oficiais do campo da saúde, à avaliação do tema por parte de juristas ou acadêmicos e sobre séries históricas de pesqui sas de opinião da sociedade brasileira sobre a legislação quanto ao aborto.

As três reportagens foram veiculadas pelos jornais Folha de S. Paulo ( 2 matérias) e O Globo (1 matéria) etinham o seguinteenquadramento: a primeira matéria da Folha, intitulada " $\mathrm{Na}$ vida pessoal, juiz decide por aborto", era sobre os dados de uma pesquisa feita pela Universidade de Campinas e pela Associação dos M agistrados Brasileiros sobre o posicionamento pessoal de magistrados quanto ao aborto. A segunda, intitulada "Aumenta a rejeição ao aborto no Brasil", também era relacionada a uma pesquisa de opinião, realizada pelo instituto de pesquisa DatafoIha em 201 municípios brasileiros. Quanto à matéria de 0 Globo, essa foi a única de todo o universo de textos recuperados e analisados a ter como tema nuclear a mortalidade de mulheres em consequência das condições precárias sob as quais o aborto clandestino é realizado no Brasil.

Os outros 15 são textos opinativos produzidos por especialistas, acadêmicos, escritores, feministas, articulistas e colunistas fixos ou esporádicos, ou são cartas publicadas de leitores. Os textos opinativos são de intei ra iniciativa de seus autores enão representam um investimento premeditado do vé́culo no sentido de disponibilizar meios, tempo eagenda de seus profissionais para a produção de pautas e reportagens que ampliem o debate sobre determinado tema. São textos produzidos por pessoas renomados em suas respectivas áreas e que, muitas vezes, sequer mantêm vínculos empregatícios ou de periodicidade de publicação de textos com esses veículos de comunicação. N esses casos, a maioria desses colaboradores contam, inclusive, com maior liberdade de expressão, por não representarem formalmente a linha editorial de tais empresas de comunicação.

Em nenhum dos textos analisados houve 0 registro de histórias de mulheres que vivenciaram o aborto, seja na condição de entrevistadas ou citadas. 0 fato de apenas 3 reportagens $(0,7 \%$ do universo geral de 434 textos e $16,7 \%$ do universo dos 18 que cotejam a relação aborto e saúde/sociedade) se referirem ao aborto de forma direta como uma questão de relevância eimpacto social no Brasil e de os demais textos mais incisivos sobre esse cenário serem de autoria de articulistas externos à redação dos veículos reite- ra o enquadramento predominante dessa prática como tema tabu moral e religioso do qual cada candidato busca esquivar-se ao máximo perante a imprensa.

\section{Conclusão}

0 agendamento do aborto pelo campo jornalístico nos quatro meses que compreenderam o período oficial da campanha eleitoral para a Presidência da República foi feito demodo secundário e pautado pelas motivações políticas e eleitorais de caráter moral e religioso das candidaturas. No universo de 434 textos analisados neste estudo, a informação maissignificativa que aponta para a exclusão dos aspectos da saúde pública do debate em torno do aborto no contexto da campanha eleitoral de 2010 é o fato de que apenas 18 textos, embora tenham sido agendados em função do enquadramento temporal dos rumos tomados pelo aborto durante a campanha, apresentavam dados que extrapolavam os limites definidos pelos protagonistas políticos no processo eleitoral. São textos que mantêm o enquadramento da campanha, mas vão um passo temático além e arriscam contemplar aspectos que não apenas aqueles pautados pelas candidaturas e seus respectivos adversários. N essa categoria inscrevem-se 3 reportagens, produzidas pelas redações dos veículos que as publicaram, estruturadas no contexto da campanha, mas contemplando dados evitados pelas candidaturas ou excluídos da discussão el eitoral .

Somente 3 textos apresentavam informações sobre 0 aborto para além dos fatos gerados em torno das campanhas, expondo dados e números obtidos através de pesquisas de opinião e retratando os índices epidemiológicos e de mortalidade de mulheres em consequência do aborto. Destes, apenas 1 reportagem levantou, problematizou e apresentou dados especificamente sobre o cenário epidemiológico e de saúde pública do aborto no país.

Durantea campanha eleitoral de 2010, 0 aborto se constituiu em tema onipresente, com lugar assegurado nas manchetes e nos textos dos veículos de imprensa. Ora essa presença se dava de maneira indireta, ora de maneira explícita. Apesar da presença ostensiva do tema nos veículos de comunicação, reproduzindo a inserção do aborto na campanha, a análise do tipo de agendamento e do enquadramento sob o qual o fenômeno era narrado e discutido revela um silêncio praticamente absoluto em relação aos aspec- 
tos da saúde da mulher, da criminalização e das consequências sanitárias e legais a serem enfrentadas por políticas públicas.

Omitidos da discussão os aspectos sanitários do aborto, o tema foi sendo conduzido no contexto interno das campanhas a partir do silêncio dos candidatos sobre esses vieses e dos destaques adquiridos pelos aspectos polêmicos em torno da perspectiva moral e religiosa. A presença do aborto, tratado pelas candidaturas como sinônimo de medo, estigma e tabu, nos textos veiculados na imprensa passou a ser contemplada predominantemente como reflexo dessas aborda- gens, com raras entradas de vozes que tratavam do aborto na esfera das políticas públicas, de autoridades que contemplam a questão e as mulheres: saúde das mulheres, direitos humanos e discussão da legislação versus criminalização. Analisando-se a cobertura dada ao aborto pela imprensa na fronteira entre o posicionamento ideológico dos candidatos eo papel social do jornalismo e dos meios de comunicação como atores sociais fundamentais para a formação da opinião pública, o que emergiu foi a construção de um discurso caracterizado pelo estigma moral e pela construção do terror e do medo religioso.

\section{Agradecimentos}

A autora agradece a D ebora Diniz, pelo estímulo e pela parceria constantes, aJ oão N eves, pelo tratamento dos dados da pesquisa de monitoramento do tema aborto na imprensa, e ao ConseIho Nacional de Desenvolvimento Científico e Tecnológico, Edital Ciências Humanas, Sociais e Sociais A plicadas. 


\section{Referências}

1. M cCombs M. A teoria da agenda: a mídia e a opinião pública. Petrópolis: Vozes; 2009.

2. M cCombs M, Shaw D. A evolução da pesquisa sobre 0 agendamento: vinte e cinco anos no mercado de idéias. In: Traquina $\mathrm{N}$, organizador. 0 poder do jornalismo - análise e textos da teoria do agendamento. Coimbra: Minerva; 2000. p. 125-145.

3. Lippmann W. O pinião pública. Petrópolis: Vozes; 2008.

4. Diniz $D$, Medeiros $M$. Itinerários e métodos do aborto ilegal em cinco capitais brasileiras. Cien Saude Colet 2012; 17(7):1671-1681.

5. Diniz D. Aborto e saúde pública no Brasil. Cad Saude Publica 2007; 23(9):1992-1993.

6. Diniz D, Medeiros M. Aborto no Brasil: uma pesquisa domiciliar com técnica da urna. Cien Saude Colet 2010; 15(Supl. 1):59-96.

7. Diniz D, Corrêa M, Squinca F, Braga KS. Aborto: 20 anos de pesquisa no Brasil. Cad Saude Publica 2009; 25(4):939-942.

8. Diniz D. Aborto e contracepção: três gerações de mulheres. In: Pinsky C, Pedro MJ, organizadores. H istória das mulheres no Brasil. São Paulo: Contexto; 2012. No prelo.

9. Diniz D, Castro R. O comércio de medicamentos de gênero na mídia impressa brasileira: misoprostol e mulheres. Cad Saude Publica 2011; 27(1):94-102.

10. Motta FM. Sonoro silêncio: por uma história etnográfica do aborto. Rev Estud Fem 2008; 16(2):681689.

11. Goffman E. Frame analysis: an essay on the organization of experience. Lebanon: N ortheastern U niversity Press of New England; 1986.
12. Entman R. Framing media power. In: D'Angelo $P$, Kuypers JA, editors. Doing news framing analysis: empirical and theoretical perspectives. New York: Routledge; 2010.

13. D'Angelo P, Kuypers JA. Doing news framing analysis: empirical and theoretical perspectives. New York: Routledge; 2010.

14. Carragee K, Roefs W. The neglect of power in recent framing research. J Commun 2004; 54(2):214233.

15. Reese SD. The framing project: a bridging model for media research revisited. J Commun 2007; 57(1):148-154.

16. Entman R. Framing bias: media in the distribution of power. J Commun 2007; 57(1):163-173.

17. D'Angelo P. News framing as a multi-paradigmatic research program: a response to Entman. J Commun 2002; 52(4):870-888.

18. Matthes J, Kohring $M$. The measurement of media frames. J Commun 2008; 58(2):258-279.

Artigo apresentado em 27/03/2012

Aprovado em 16/04/2012

Versão final apresentada em 18/04/2012 